\title{
A three-levels analysis of double stimulation in a Change Laboratory
}

\author{
Daniele Morselli
}

Faculty of Education, Free University of Bozen-Bolzano, Bolzano, Italy

\begin{abstract}
Purpose - The purpose of this paper is to operationalise and apply a three-level analysis of double stimulation in a Change Laboratory with teachers.

Design/methodology/approach - Within qualitative inquiry, this Change Laboratory intervention was conducted as case study, by way of an intensive analysis of an individual unit. The macro-level deals with the societal problem and the collective solution found to tackle it. An intermediate level looks at the Change Laboratory as a methodology able to boost expansive learning through chains of first and second stimuli. The micro-level analyses the participants' interactions during the sessions and traces the terms connected to the first and second stimulus.

Findings - This analysis suggests that the conflicts of motives experienced by the participants at the micro level refer to the aggravated contradiction identified at the macro level. Conflicts of motives seem to be superior in number during the first block of sessions, when the first stimuli are analysed. The micro analysis indicates the 6th session as the turning point of the intervention, when the participants take the auxiliary stimulus and turn it into and effective and meaningful sign. The intermediate level helps to trace the third transition from the formation of the second stimulus to its implementation, reflection upon and further development and generalisation.

Originality/value - Vygotsky's method of double stimulation is crucial to develop one's agency and to explain how individuals deliberately influence events. Yet the literature is fragmented and made of brief accounts, and this paper for the first time inspects double stimulation on different levels within a Change Laboratory intervention with teachers.
\end{abstract}

Keywords Agency, Change Laboratory, CHAT, Qualitative inquiry, Double stimulation

Paper type Research paper

\section{Introduction}

Currently, it is recognised that agency is an element influencing change in education (Kumpulainen et al., 2018). Agency is crucial to develop active learning and generate change at the various levels of school (Juutilainen et al., 2018; Tao and Gao, 2017; Wallen and Tormey, 2019). Within Vygotskyan studies, double stimulation is foundational for the development of agency and to explain how individuals change deliberately their events (Sannino, 2015). Double stimulation is used in formative interventions, especially the Change Laboratory, to promote expansive learning and collective transformative agency (Sannino et al., 2016). While diverse authors advocated for double stimulation as an epistemic

(C) Daniele Morselli. Published by Emerald Publishing Limited. This article is published under the Creative Commons Attribution (CC BY 4.0) license. Anyone may reproduce, distribute, translate and create derivative works of this article (for both commercial and non-commercial purposes), subject to full attribution to the original publication and authors. The full terms of this license may be seen at http://creativecommons.org/licences/by/4.0/legalcode

This work was supported by the Open Access Publishing Fund of the Free University of BozenBolzano.

Received 1 August 2020 Revised 15 November 2020 Accepted 12 February 2021 
JWL 33,7

principle characterising the Change Laboratory (Engeström, 2007, 2011; Engeström and Sannino, 2010; Sannino et al., 2016), yet a comprehensive analysis of this process is missing.

Provided that "in the Change Laboratory, the principle of double stimulation is applied on several levels" (Virkkunen and Newnham, 2013, p. 48), this explorative study seeks to operationalise and then apply a three-level analysis of double stimulation in a Change Laboratory intervention with teachers. It starts with a literature review on double stimulation, formative interventions and the Change Laboratory, then it introduces the case study, a technical institute in Italy with teachers that between 2016 and 2017 had to deal with the progressive drop of new enrolments students, thing that was bound to cause the disappearance of their surveying course. The paper shows three possible levels of analysis of double stimulation - macro, intermediate and micro in a Change Laboratory intervention and subsequently explains how they contribute to tracing the three main transitions of double stimulation as suggested by Engeström et al. (2014).

\section{Literature review}

\subsection{Agency and double stimulation}

The study of agency has come recently to the fore in professional and workplace learning to promote meaningful careers and lifelong learning, so individuals develop skills in effectively adapting to changes they face (Eteläpelto et al., 2013). The expectation that education should promote agency in individuals, however, has been an assumption in Western societies since the enlightenment (Lipponen and Kumpulainen, 2011). The OECD Learning Framework (OECD, 2018) defines agency as "a sense of responsibility to participate in the world and, in so doing, to influence people, events and circumstances for the better" (p. 4). In education teachers can develop agency by designing course programs around students and by motivating them by acknowledging their previous competences and values. Lipponen and Kumpulainen (2011) argue that agency is of utmost importance for teachers if they want to go beyond delivering programs to students, having the will to develop their competences in a lifelong learning perspective and the ability to deal with increasingly challenging school situations. Additionally, agency plays an important role in a teacher's identity (Priestley et al., 2015) and a relational agency (Edwards, 2005) is essential when crossing the boundaries to cooperate with other professionals. This agency is further cultivated through the support and tools provided by the other actors involved in a problematic situation.

While there are different perspectives to study professional agency (Eteläpelto $e t$ al., 2013), the socio-cultural perspective conceptualises it as a social and collective phenomenon and, in line with the Vygotskian legacy, gives particular importance to the tools that mediate the individuals' action. Within these studies double stimulation plays a crucial role to conceptualise agency, not just in interpretations, studies and commentaries of Vygotsky's studies (Sannino, 2015) but also because double stimulation is considered "the mechanism with which human beings can intentionally break out of a conflicting situation and change their circumstances or solve difficult problems" (Sannino, 2011, p. 584). To prove how pervasive double stimulation is to regulate human behaviour in everyday life, Vygotsky (1978) makes the examples of tying a knot as a reminder or throwing one dice to make a difficult choice. In experimental settings on double stimulation, the person was guided actively to construct a new mean to solve a problem (van der Veer and Valsiner, 1991). Vygotsky, for example, gave a child a problem beyond her actual abilities and placed an object next to her (Sannino, 2015), and he frequently observed that such object from neutral acquired a role to solve the problematic situation.

Sannino argues that two valuable aspects of double stimulation have been often overlooked by research. Firstly, besides being a method, double stimulation is a principle of 
volition distinguishing the higher mental functions. Volition refers to the willpower required to overcome hindrances, as an action is volitional only when there are obstacles to carry it out. Secondly, not only encompasses double stimulation two stimuli but also a conflict of motives. This conundrum represents, together with a challenging situation, the starting point with which humans intentionally regulate their behaviour and affect the world around them. For Sannino (2015, p. 8):

Conflict of motives implies a clash between opposite aspirations or tendencies which occur in situations involving uncertainty in which one is or about one's own conduct and requiring the courage of a deliberate choice.

Such volitional actions are for Vygotsky (1997; in Engeström, 2007, pp. 365-366) characterised by two phases or apparatuses. During Apparatus 1, or the design phase, the individual actively designs the mediating artefact. During the subsequent Apparatus 2 or execution phase, the individual turns into action what has been planned in Apparatus 1, and this looks almost effortless and quasi automated.

Sannino (2015) has turned double stimulation into a model, which has been tested in experimental situations involving uncertainty to inspect the emergence of volitional action in individuals (Sannino and Laitinen, 2015) and in small groups (Sannino, 2016). In the waiting experiment (or meaningless situation), the subject is left in an empty room with no instructions: triggered by this situation that acts as first stimulus, the subject must decide. Very often he or she brings a neutral stimulus into this situation (such as the clock in the room) giving a new sense to it and decides that when the thins will have reached an established position, he or she will take the initiative and leave the room. The waiting experiment shows that the researcher has not necessarily to provide the subject with readymade second stimuli and that double stimulation is an open-ended process that can be hardly controlled externally. Furthermore, Ivaldi and Scaratti (2016) suggest that the waiting experiment can be taken as prototype of problematic situations that organisation often face, when its employees have to find new ideas and solutions to manage contradictions and problematic situations.

\subsection{Formative interventions and the Change Laboratory}

Within the Vygotskian legacy double stimulation has been recently investigated in relation to natural activities such as in encounters between home care workers and their elderly clients (Engeström et al., 2015), in services for families with children at risks (Hopwood and Gottschalk, 2017) and in leadership development in early child education (Nuttall et al., 2018). Most importantly, the application of double stimulation to foster change and innovation brings radically new forms of interventions (Sannino and Sutter, 2011). Considering the participants' agency brings a new determinant in causes of formative interventions, which are characterised in the starting point, in the process, in the outcome and in the different role of the researcher (Engeström, 2011). Firstly, the participants confront a contradictory or problematic object inserted in their activity, which they analyse and expand by designing a new model. It is not, therefore, possible to know at the beginning of the intervention what the result will be like. Secondly, the intervention is negotiated with the participants who progressively take charge of it. Thirdly, the purpose is to construct a new model of activity and develop the participants' agency. Fourthly, acting as facilitator, the researcher seeks to promote an expansive transformation.

Hence, formative interventions boost a new type of learning that involves collectives and networks where the participants learn something that is not yet there (Engeström and Sannino, 2010). Expansive learning is generated when the practitioners face a cogent 
JWL 33,7

problem calling for a profound transformation of their activity: initially they start questioning the present state of things and logics, and while more actors join the change effort in, they start and perform a collaborative analysis aiming at conceiving and implementing a new model of activity. There are seven learning actions that together form a whole expansive learning cycle, these are (p. 7): question the present practices, analyse them from an historical and empirical point of view, model the new solution that tackles the basic contradiction affecting the organisation, examine and test the new model, implement the model, reflect on the process and consolidate and generalise the new practice. Because the dialectical concept of contradiction represents the driving force of transformation in activity systems, during formative interventions the participants articulate and engage with the contradictions of their organisation to model a new activity.

Although cycles of expansive learning take place over years in organisations, formative interventions seek to support expansive learning in shorter periods of time (Engeström, 2020). During Change Laboratory interventions, for example, 15-20 practitioners meet once a week for 8-10 sessions, plus follow up. The basic idea is to prepare on the shop floor a space with a rich instrumentation to help analyse problems and design new models of work activity (Engeström et al., 1996). The main tool is a $3 \times 3$ set of writing surfaces (such as flipcharts) used for joint analysis of the activity according to a horizontal and a vertical dimension. The horizontal dimension represents different levels of abstraction. At one hand there are mirrors, video-taped materials of problematic situations and innovative solutions gathered on the field to provide stimulation for discussion. Mirror materials can be interviews, statistics, stories and/or performance charts concerning the system of activity under scrutiny. At the other end, the model/vision surface serves for conceptual analysis and theoretical tools such. To this end the facilitator can propose the triangular model of human activity (Engeström, 2015, p. 63) and the cycle of expansive learning (Engeström, 1999, p. 384). The intermediate surface is for tools and ideas. Similarly, the vertical dimension of the writing surfaces is used for a temporal analysis through past, present and future of the activity system under scrutiny. Each session is video recorded for research aims and to review critical episodes in subsequent sessions.

When used in the Change Laboratory, contend Virkkunen and Newnham (2013), double stimulation becomes a more complex, multifaceted and time-consuming process than in the individual action of remediation as studied by Vygotsky (1978) or experimented with by Sannino and Laitinen (2015) in the waiting experiment. Consequently, in formative interventions the process of double stimulation can be traced by studying three transitions (Engeström et al., 2014). The first development is from the systematic contradiction to the conflict of motives experienced by the participants. The second transition is from the conflict of motives characterising the first stimulus to the search for a potential auxiliary stimulus, provided that this process is open ended, and it is improbable that the auxiliary stimulus provided by the facilitator will be taken as it is by the participants. The third evolution starts from the formation of the second stimulus, which is meaningful for the participants, to its actual implementation in the resolution of the aggravated contradiction identified during the sessions.

\subsection{Research on different levels used to analyse double stimulation in Change Laboratory interventions}

This section reviews the analyses of double stimulation in Change Laboratory interventions according to three levels: the level of the overall formative intervention which is called macro level; the level of the sessions named intermediate; and a micro level of the conversations during the sessions. 
2.3.1 Macro level. At the level of the overall intervention, a study from Sannino et al. (2016) compared three formative interventions according to the following concepts: first stimuli, conflict of motives, second stimuli and practical experimentation examples. Sannino and Engeström (2017) compared three Change Laboratory interventions through the concepts of contradictions, conflict of motives, first and second stimuli, zone of proximal development. The macro level can hence focus on first and second stimuli. In this regard, Engeström (2007) suggests that during the sessions the first stimulus is acknowledged and recognised by the participants, while for Virkkunen and Newnham (2013), the participants encounter and build a common first stimulus, which effectively builds a "consciousness of the problem that needs to be solved" (p. 49). Regarding the second stimulus, Sannino et al. (2016) refer to it as a key artefact that is used by participants to plan the future of their activity and to take concrete actions to make that future happen; it is this construction process that generates the agency for the collective change effort (Engeström and Sannino, 2016). Moreover, Engeström (2011) claims that a second stimulus requires four characteristics to be effective: it is intentionally designed by the participants; initially it is formulated in a vague fashion and is progressively enriched with sense; it functions as an anchoring device, as it is a relatively durable artefact and is designed with the aim of addressing the challenge generated by the aggravated contraction that is shown by the first stimulus. As a result, acknowledging and discussing the aggravated contradictions as structural and historically accumulated tensions represent the connecting element between the first and second stimuli (Ivaldi and Scaratti, 2016).

2.3.2 Intermediate level. At the level of the sessions, double stimulation supports the step-by-step process between the acknowledgment of the issues to be tackled and the design of a new model of activity (Virkkunen and Newnham, 2013, p. 80). It is the facilitator who facilitates this process by setting tasks that encourage the participants to take the appropriate expansive learning actions. Effective tasks are planned by considering the following elements: the first stimuli, which often mirrors of the activity; a question or assignment about this mirror to encourage the construction of a shared first stimulus; the second stimuli, which includes analytic methods or tools that help participants deal with the first stimulus; the social organisation of the task; how to document the task; and the way results are discussed. Engeström (2007) adds that the first stimuli of Vygotskyan design are the mirrors, which depict a disturbance, a critical incident or a challenging problem stemming from the activity. The second stimuli are conceptual tools that facilitate analysis and problem resolution, provided that the participants end up agreeing on the construction of their second stimulus (Engeström, 2011).

2.3.3 Micro level. This level relies on of the transcripts of the sessions to look for instances of double stimulation. Sannino and Engeström (2017), for example, counted the number of times that the second stimulus (in that case "knot" and "knotworking") had occurred throughout the sessions. Morselli and Sannino (2021) applied Sannino's (2015) model of double stimulation to a Change Laboratory, thus focusing on the four phases that characterise the first apparatus of double stimulation. Moreover, using Engeström and Sannino's (2011) discursive manifestations of contradictions, Ivaldi and Scaratti (2020) sought to connect the first stimuli with the dilemmas experienced by the participants.

\section{Methods}

Within qualitative inquiry (Denzin and Lincoln, 2018), this Change Laboratory intervention was conducted as case study, by way of an intensive analysis of an individual unit. Overall, this intervention took place in a technical secondary school situated in the Lombardy region in Italy between 2015 and 2018. The Change Laboratory took place as in-service training with eight sessions between February and April 2016 and was followed by three follow-up 
JWL

33,7

510

meetings in May 2016, October 2016 and May 2017. The intervention was facilitated by the author of this paper. Concerning the history of the school, it was founded at the beginning of the 1970s as an institute for sole surveyors. After the school reform of 2008, however, from one course in surveying, the school had started delivering three courses (graphics, logistics and surveying). From this reform the number of new enrolment students in surveying had dropped year after year from 104 students in 2008 to 26 in 2015. By way of contrast, the number of new enrolments in Graphics had been constantly soaring, thus becoming the primary course of the institute.

The researcher had become an international grant to carry out the Change Laboratory intervention, and the school was chosen as the researcher had already carried out there diverse researches and had consequently gained the trust from the school director and the teachers. Additionally, the school director saw the project as a flagship to promote the school but also to ignite the teachers' sense of initiative. It was decided to start the intervention with three months of observant participation. The aim was on the one hand, to find the course or class that would have benefitted the most from the intervention, with the condition that the teachers' participation would have been fully voluntary. This period also allowed the researcher to understand the school problems and dynamics from within and to gather the mirror materials to be used during the Change Laboratory. An initial group of 14 teachers and workshop assistants engaged in the Change Laboratory with the aim of tackling the issue of the lack of new students' enrolments in their surveying course, which was threatening the existence of their course itself. Most of these teachers taught technical subjects such as design, topography and land valuation but teachers of literature, English and maths also took part to the sessions although more sporadically. Some workshop assistants left, and new staff were appointed because of the turnover of fixed contract personnel. During the eight sessions, which was also a technical council, the teachers approved the interdisciplinary project by majority and more teachers joined to implement the solution in two Grade 13 classes, which was repeated for two school years, in 2016-2017 and in 2017-2018.

\section{Results}

Section 4 shows the results according to the three levels of analysis described in the literature review.

\subsection{Macro level for the identification of the first and second stimuli}

This level of analysis entails a first stimulus as a joint awareness of the problem to be dealt with, a second stimulus as the mediating artefact that is transformed into a meaningful sign to tackle that challenge and the aggravated contradiction affecting the activity system that the joint analysis made evident, thus connecting first and second stimulus. Table 1 presents this analysis applied to the present CL.

\begin{tabular}{|c|c|c|}
\hline \multirow[t]{2}{*}{ Apparatus 1} & First stimulus & $\begin{array}{l}\text { The falling number of new enrolment students in the surveying } \\
\text { course }\end{array}$ \\
\hline & Second stimulus & $\begin{array}{l}\text { An interdisciplinary project to be delivered by teachers and } \\
\text { workshop assistants in the two } 5 \text { th Grade classes during the } \\
\text { whole school year. The project is realistic and relevant for the } \\
\text { surveying profession, and entails diverse issues pertaining the } \\
\text { construction of a new building seen in a holistic way. Besides } \\
\text { technical subjects (Design, Land Valuation and Topography) it } \\
\text { integrates Humanities such as Literature and English }\end{array}$ \\
\hline
\end{tabular}

Table 1.

Macro level 
Regarding the first stimulus, the teachers had a clear idea of the shared problem they wanted to address:

\section{Change \\ Laboratory}

7 (1st meeting)

Design teacher 1
Compared to our tradition where we had four 1st Grade classes and sometimes five, we arrived to a situation where perhaps this year we will have two classes, last year we had only one, which therefore indicated a big drop of enrolments [...]

Hence the problem was the declining number of new enrolments which had put the surveying course and their jobs at risk. During the first meetings the participants dig into the causes for that also from an historical perspective, which allowed to identify and conceptualise the aggravated contradiction that was pervading their course considered as an activity system. The turning point for the participants is the school reform of 2008:

602 (4th session):

Design teacher 2

\begin{abstract}
The right word to characterise the reform is disorientation, since many of us do not agree with it, we do not think it is valid but rather damaging. The fact that our course is not finalised anymore to prepare a technician left us puzzled
\end{abstract}

The teachers were still teaching for knowledge in "compartmentalised" subjects, as before the reform, and consequently the students had a fragmented and unconnected vision of surveying, as explained well by the following quote:

68 (4th session):

Land valuation teacher 2
It is one issue that I see every day, the fact that students do not have the transversality of surveying. I teach land valuation, and this is one thing (for them), you teach construction and this another thing. When you ask them a question from another topic - for example, from topography - they fail. This is a big problem, because one day in the workplace they will have to be able to deal with (surveying as holistic subject)

However, in this way the teachers did not have to cooperate with each other, as each dealt with their prearranged subjects. The favourite didactic was the lecture, which meant that even the workshops were conducted this way, as a result the figure of the workshop assistant introduced by the reform was considered useless. The awareness on the lack of cooperation between them and the use of old-fashioned didactics is evident in the following excerpt:

441 (5th session):

Design teacher 1

444 Land valuation teacher 1

445 Design teacher 1
Our weakness is this, because in the truth it suits us to meet not too often ...

About working together, we do not know how to have the student work together

(This is) primarily because we never work together 
JWL 33,7

\section{2}

By way of contrast, the reform had called for teaching for competence, that is teaching for interdisciplinary projects with realistic activities that better prepared students for their profession with a holistic view of surveying. This required more cooperation with the colleagues in planning joint activities, as well as active didactics able to involve the students. Following the reform, the presence of the workshop assistants in the classroom represented for the teachers an issue, since they were an unexploited resource:

\begin{tabular}{ll}
\hline $604\left(2^{\text {nd }}\right.$ session $)$ & Their presence (following the reform) left us confused. We \\
Topography teacher 1 & found ourselves with these co-workers that we had many \\
& years ago $[\ldots]$. \\
627 & And to be sincere, now we are used to teach without them.
\end{tabular}

The second stimulus resolved this aggravated contradiction from different perspectives: in the tools, with new students-didactics; in the division of labour, with a prominent role of the workshop assistants, and in the rules, with a call for cooperation among teachers to design and deliver together an interdisciplinary project. Finally, the excursions and realistic work of surveying and designing a new building was a way to advertise their course, not only with the students' work of mouth, but also during the school open days. The topography teacher summarises how the second stimulus handles the main contradiction:

\footnotetext{
415 (6th session) Yes, but with the interdisciplinary project we show that we work all together and that the Topography students can make a synthesis (and connect) all that they know. We will show it (during teacher 1 the open days) when we present the school and see whether we concretise something (in terms of new enrolments) [...]
}

\subsection{Intermediate level of the sessions}

A possible analysis of double stimulation at an intermediate level of the sessions as shown in Table 2 focuses on this step-by-step process that makes it possible finding an expansive solution, and it is based on the elements suggested by Virkkunen and Newnham (2013) in preparing tasks that encourage specific expansive learning actions.

Table 2 reconstructs double stimulation as a chain of potential first and second stimuli to promote specific expansive learning actions during the overall intervention, therefore, throughout and beyond the sessions. The first column lists the session number and next there are the expansive learning actions (Engeström and Sannino, 2010) between and after the sessions. For example, the teachers carry out an assignment in their own time between the 5th and the 6th session, to envision the future of their course; between the 8th and 9 th sessions, they test new didactics connected to the new model in a couple of classes; and between the 10th and 11th sessions they implement the new model throughout the school year 2016-2017. The second column reports for each session the overall expansive learning action as planned by the researcher or established by a judgement based on the analysis of the transcripts and the results of each session.

Table 2 lists subsequently: the task or objective of the session; potential first and second stimuli, and how the result of the learning action is documented. The task or objective of the session was established by the facilitator $(\mathrm{F})$ or by the participants $(\mathrm{P})$. Concerning potential first stimuli, they were mostly offered by the facilitator in the form of mirror material, as well as sometimes being prompted by the teachers, such as when they suggested which 

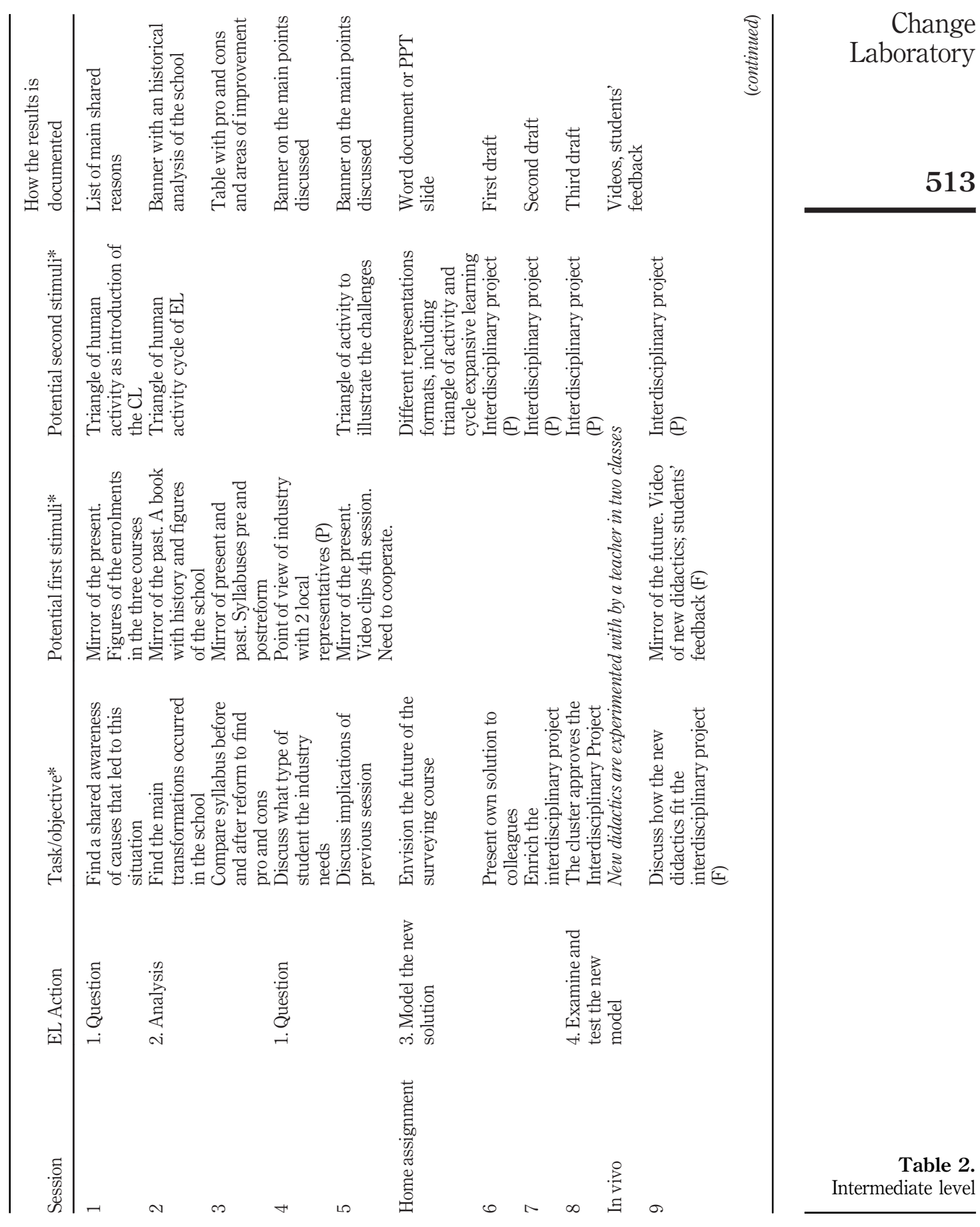

Table 2. Intermediate level 
JWL
33,7

514

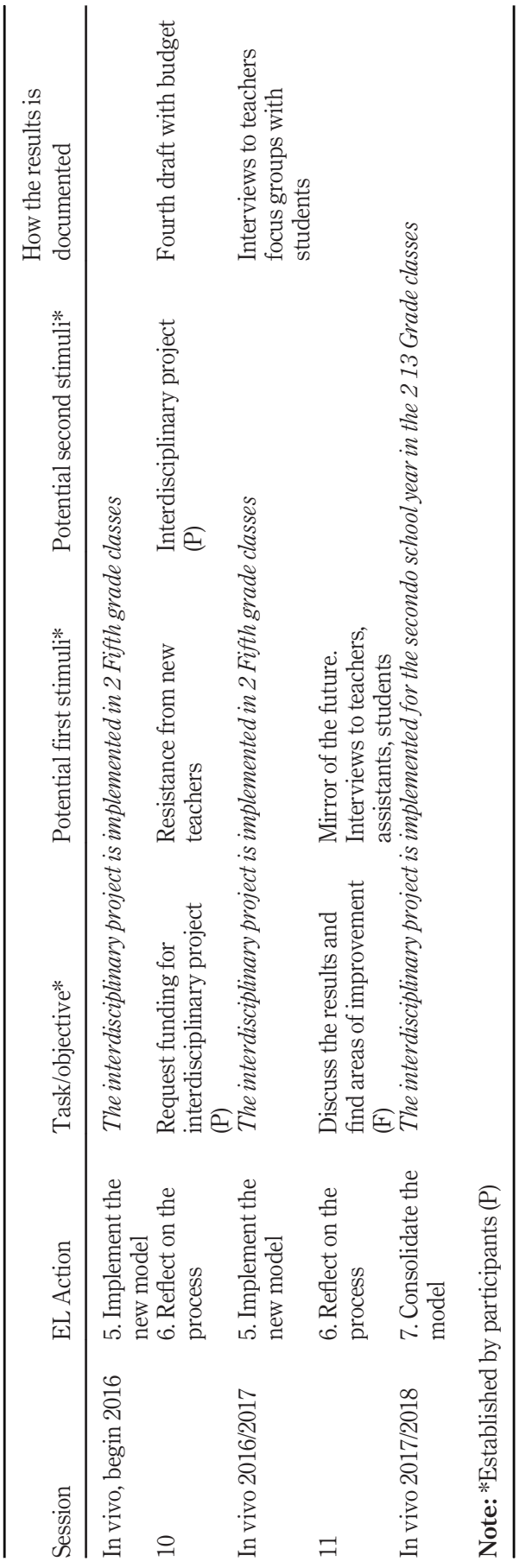

Table 2. 
industry representatives to invite (5th session). Regarding potential second stimuli, at the beginning it was the facilitator who offered possible models such as the triangle of human activity and the cycle of expansive learning as suggested by Engeström (2007) as well as by Virkkunen and Newnham (2013). The latest column on the left shows how the expansive learning action was documented. This could be the result of the session, for example, a banner, or it could be a draft version of the second stimulus.

\subsection{Micro level}

A conversational level concentrates on the transcripts of the sessions, in this intervention 6.967 speaking turns that have been fully transcribed. Starting from the analysis of Sannino and Engeström (2017) focusing on the number of occurrences of the second stimulus in the transcript, the analysis reported in Table 3 focuses on key terms related to both 1st and 2nd stimulus. While in the transcript there is only one term for the second stimulus, that is "interdisciplinary project", and therefore, it can be easily counted in the transcripts, the analysis of the first stimulus is more complex and featured a search for "rudimentary cues" (Engeström and Sannino, 2011), which in this case were proxy words closely connected to the first stimulus identified through multiple readings of the transcripts. These key concepts: the "crisis" involving the surveying course, the school "reform" of 2008, and the "promotion" of the surveying course - or better the lack of it.

While the problem that the participants tackled was clear (that is, the drop of enrolments) this key term is mostly used in the first session. In the following sessions, the participants discuss its causes while they advance in the expansive learning process and conceptualise the aggravated contradiction. Table 3 indicates that the words related to the first stimulus are particularly mentioned during the first block of sessions and then fade out. Concerning the second stimulus, the word "interdisciplinary project" characterises the second half of the intervention but is also mentioned sometimes in the first half because it was a practice of the past:

728 (2nd session)

Topography teacher 1
Yes, we have the issue of (the lack of) time, we must do the same number of things (we did before the reform) in less time, and so we are stressed. Working in team around an interdisciplinary project has always been interesting but required a bit too much time

Yet in the fourth session the interdisciplinary project is considered by the participants just an auxiliary stimulus:

239 (4th session)

Land valuation teacher 2
Since we cannot think of an interdisciplinary project, what about joint lessons? [ . . . but this without making an interdisciplinary project since there is not enough time

It is only in the sixth session that this auxiliary stimulus becomes a meaningful sign to tackle the contradiction that the participants have identified and only then becomes it the second stimulus. Here is the turning point where the idea starts to take shape: 
JWL

33,7

516

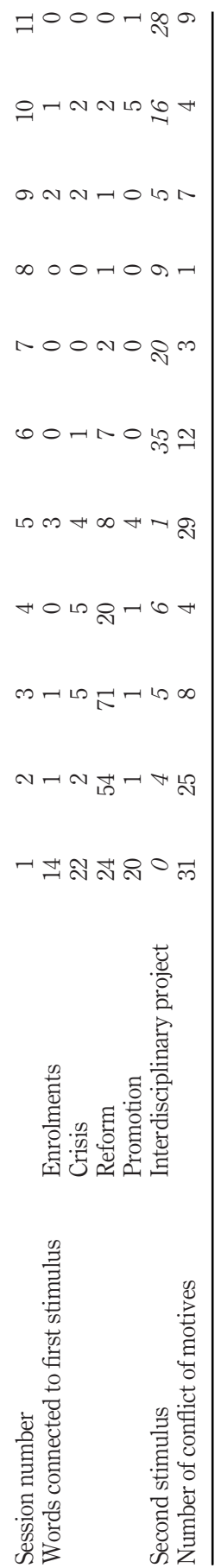

Table 3.

Micro level with occurrences of key terms related first and second stimulus 
239 (6th session)

Land valuation teacher 1
[. . . ] I suggest resuming the old interdisciplinary project I used (many years ago) both in Agronomy and here [... . I propose to have 3 hours (on a weekly basis) together, but we could do it in a different way, for example $2 \mathrm{~h}$ of Design and 1 $\mathrm{h}$ of Land Valuation ... in any case together and with a workshop assistant as coordinator [...]

\section{Change Laboratory}

Beyond the analysis of rudimentary cues connected to the first and second stimulus, Table 3 shows the number of conflict of motives experienced by the participants during the sessions (Sannino, 2008), bearing in mind that "conflicts may certainly different degrees of explicitness and tensions; they should, therefore, not be an absolute category" (Sannino, 2015, p. 8). However, these conflicts of motives seem to follow a pattern. They are more widespread in the first block of sessions; however, they do not disappear in the second block when the second stimulus is being enriched. The following quotes are examples of conflicts of stimuli in the first block of sessions:

78 (1st session)

Literature teacher

865 (2nd session)

Land Evaluation teacher 3

864 (3rd session)

Design teacher 1

69 (5th session)

Topography teacher 1
Our problem was what do we do now and what is our role? What type of students do we train? What will they do after the end of their study? They cannot do anything, they cannot do this, they cannot do that. I think that these dilemmas have conditioned us negatively I try my best to involve the students to visit a stand at the student's trade fair, but then a colleague tells them in the class "don't lose your time there". [.. .] I say one thing, one colleague says another, without establishing a common strategy [...]

[...] someone told us "you (just) study the (new) topic", but what is the sense of that? What is the sense of studying a new content at my age, have I to transmit competencies or just knowledge? [. . . ]

We are aware that our students will find a job, and we knew already the things that the experts of the industry told us. How we can have the world understand that, even though there is the crisis in the building sector, the technician that we train is still essential (for the industry)?

The first and the last quotations manifest loss of the original sense of the work (Virkkunen and Newnham, 2013, p. 106) that characterises the most experienced participants that did not understood the sense of the reform. The third quotation is still connected to the school reform, which imposed this experienced teacher to teach subjects he did not know about, while the second testifies for the apparent lack of coordination among the teaching body, who end up by criticising each other in front of the students. Most importantly, there is a clear connection between these conflicts of motives experienced by the participants and the aggravated contradiction, as the quotes deal with the changes imposed by the school reform. The first and last quotes deal with the changed object represented by the new type of professional that the teachers want to train, second quote is related to lack of cooperation between teachers, while the third quote about difficulty to teach new subjects differently. 
The following quotations came from the second block of sessions:

324 (7th session)

Workshop assistant
217 (8th session) Design teacher 2

199 (10th session) Land Valuation 3 86 (11th session) Design Teacher 3
I understand. But we often say that requalification is the future of the construction industry and then we never speak about it. How can our students to be trained in the skills they will need?

We had regrets for the interdisciplinary project that we had often let manifest

For care? I am sick of doing things just because I must

The students' group work is useful only when each component (of the group) does their job and then shares with the other components, so they all share responsibilities. This has been done, and yet I do not know how I could have done it differently (better)

In the first quote the topic of the interdisciplinary project is being disputed: on the one hand everybody agrees one job of the surveyor is the requalification of buildings, on the other hand the interdisciplinary project rules this out. The second quote manifests regret for not having done the project before; the third comes from a teacher who feels forced to participate in the project, while the fourth quote is from a teacher who feels that the new didactics did not bring the expected result. Again, these quotes are all related to the main contradiction that the new project seeks to handle. Additionally, an analysis of the third-type contradiction that the new project was facing is reported in (Morselli, 2019).

\section{Discussion}

The starting point of the analysis of double stimulation in a Change Laboratory intervention is at the whole level of intervention and mirrors the analysis made by Sannino et al. (2016) and Sannino and Engeström (2017). Table 1 shows the result of an interpretive analysis (Denzin and Lincoln, 2018) that in the light of activity theory seeks to figure out the first and second stimuli and the connecting element, the contradiction affecting the activity system.

Based on Virkkunen and Newnham's (2013) schema on the preparation of the expansive learning tasks, the intermediate level reconstructs how each meeting was planned, the expansive learning action pursued, and the result obtained. It displays the connection between double stimulation and expansive learning actions, in line with Virkkunen and Newnham. Table 2 also shows the development of the participants agency in line with Sannino et al. (2016). At the beginning, it is the facilitator who proposes the tasks to perform, but in the 4th session the participants suggest which expert they want to summon, and from the 6th session they decide to target an interdisciplinary project, thus displaying the connection between elaboration of own second stimulus and take of agency, as suggested by Engeström (2011). Table 2 also displays how the second stimulus is progressively formulated and enriched during the intervention, but also the actions taken in vivo for its implementation, as suggested by Engeström (2011). As such it is also a decision to act in a certain way (Engeström et al., 2014) and the implementation is performed the following school year as established during the sessions.

The micro level displays how the first stimulus is elaborated upon during the sessions as suggested by Virkkunen and Newnham (2013). Concerning the second stimulus, in this intervention the idea of an interdisciplinary project is already present from the second session, however, just in form of an auxiliary stimulus (Engeström, 2011; Sannino, 2015) not yet meaningful for the solution of the problem. Similarly to Sannino and Engeström (2017), 
the second stimulus changes in meaning during the intervention: in the first block of sessions it refers to good practices from the past in the school and in other institutes, in the second block of sessions it represents the solution to the problem. The turning point happens in the 6th sessions, when the participants finally manage their meaningless situation (Ivaldi and Scaratti, 2016) and, through the concept of interdisciplinary project, turn such meaningless situation into one that has sense for them (Sannino, 2008). At the micro level, this activity traces the expressions of the conflict of motives throughout the sessions; these are related to the analysis and progressive discovery of the main contradiction through the whole intervention but seem to be superior in number during the first block of sessions, when the first stimuli are analysed.

\section{Conclusions}

Schools have a tremendous and unexploited potential to renew society (Engeström, 2020). This article analysed double stimulation in a Change Laboratory with teachers, thus starting to inspect the multi-layered nature of double stimulation as suggested by Virkkunen and Newnham (2013) and Engeström (2011). The macro level deals with the societal problem, and how the historical challenge experienced by teachers can be understood in terms of contradictions. An intermediate level at the timeframe of the sessions looks at the Change Laboratory as a methodology able to boost an expansive learning cycle through chains of first and second stimuli. Firstly, it reconstructs first and second stimuli; therefore, it displays the use of the tools and concepts to re-mediate the activity as contended by Virkkunen (2006), and gives an idea of the diverse artefacts created in the process. Secondly, it shows the chain of double stimulation leading to specific expansive learning actions as suggested by Virkkunen and Newnham (2013). Beyond the sessions, it also studies the learning action of consolidating the new practice, and so far only Sannino et al. (2016) investigated the long-term consequences of a Change Laboratory intervention. A possible micro level analyses the transcripts of the sessions to find occurrences of first and second stimulus as well as occurrences of conflict of motives.

These three levels can be useful to inspect three transitions of double stimulation in the Change Laboratory as suggested by Engeström et al. (2014). The first transition is from the aggravated contradiction to the conflict of motives, and this analysis has shown that the conflict of motives at the micro level referred to the main contradiction identified at the macro level. The second transition refers to the conflict of motives experienced during the elaboration of the first stimulus to the identification of an auxiliary stimulus. In this intervention, the micro analysis indicates the 6th session is the turning point of the intervention (Ivaldi and Scaratti, 2016), when the participants take the auxiliary stimulus of interdisciplinary project and turn it into an effective and meaningful sign. Here comes into play the third transition of double stimulation envisioned by Engeström et al. (2014), from the formation of the second stimulus to its implementation, reflection upon and further development and generalisation, and the intermediate level helps to trace this process. Concerning the conflict of motives at the micro level, they do not disappear in the second block of sessions. It could be then hypothesized that conflicts of motive characterise not only the first and second transition, but also the third although in smaller magnitude.

Future studies will have to confirm the findings of the analyses carried out in this paper, thus showing their heuristic value. Although three levels have been used to describe this intervention, other levels may emerge as important or may be needed in other formative interventions. The intermediate level, for example, considered that each session was characterised by a certain expansive learning action as planned by the facilitator (Virkkunen and Newnham, 2013), while an analysis at the transcript level of a Change 
JWL 33,7

Laboratory intervention carried out by Engeström et al. (2013) showed that each session was indeed punctuated by diverse learning actions. Moreover, while this level traced the evolution of the teachers' agency through looking at the level of the sessions, other similar analyses could trace the participants' digressions from the facilitator's plan as suggested by Engeström (2011).

\section{References}

Denzin, N.K. and Lincoln, Y.S. (2018), "Introduction: the discipline and practice of qualitative research", in Denzin, N.K. and Lincoln, Y.S. (Eds), The Sage Hjandbook of Qualitative Research, Sage, Vol. 5, Thousand Oaks, CA, pp. 1-35.

Edwards, A. (2005), "Relational agency: Learning to be a resourceful practitioner", International Journal of Educational Research, Vol. 43 No. 3, pp. 168-182.

Engeström, Y. (1999), "Innovative learning in work teams: Analysing cycles of knowledge creation in practice", in Engeström, Y., Miettinen, R. and Punamäki, R.L. (Eds), Perspectives on Activity Theory, Cambridge University, pp. 377-404.

Engeström, Y. (2007), "Putting vygotsky to work: the change laboratory as an application of double stimulation", in Harry, D., Michael, C. and James V, W. (Eds), The Cambridge Companion to Vygotsky, Cambridge University, pp. 363-382.

Engeström, Y. (2011), "From design experiments to formative interventions", Theory and Psychology, Vol. 21 No. 5, pp. 598-628.

Engeström, Y. (2015), Learning by Expanding, Cambridge University.

Engeström, Y. (2020), "Ascending from the abstract to the concrete as a principle of expansive learning”, Psychological Science and Education, Vol. 25 No. 5, pp. 31-43.

Engeström, Y., Virkkunen, J., Helle, M., Pihlaja, J. and Poikela, R. (1996), "The change laboratory as a tool for transforming work", Lifelong Learning in Europe, Vol. 1 No. 2, pp. 10-17.

Engeström, Y. and Sannino, A. (2010), "Studies of expansive learning: Foundations, findings and future challenges", Educational Research Review, Vol. 5 No. 1, pp. 1-24.

Engeström, Y., Rantavuori, J. and Kerosuo, H. (2013), "Expansive learning in a library: Actions, cycles and deviations from instructional intentions”, Vocations and Learning, Vol. 6 No. 1, pp. 81-106.

Engeström, Y., Sannino, A. and Virkkunen, J. (2014), "On the methodological demands of formative interventions", Mind, Culture and Activity, Vol. 21 No. 2, pp. 118-128.

Engeström, Y., Kajamaa, A. and Nummijoki, J. (2015), "Double stimulation in everyday work: Critical encounters between home care workers and their elderly clients", Learning, Culture and Social Interaction, Vol. 4, pp. 48-61.

Engeström, Y. and Sannino, A. (2016), "Expansive learning on the move: insights from ongoing research/El aprendizaje expansivo en movimiento: aportaciones de la investigación en curso", Infancia y Aprendizaje, Vol. 39 No. 3, pp. 401-435.

Eteläpelto, A., Vähäsantanen, K., Hökkä, P. and Paloniemi, S.J. (2013), "What is agency? Conceptualizing professional agency at work”, Educational Research Review, Vol. 10, pp. 45-65.

Hopwood, N. and Gottschalk, B. (2017), "Double stimulation "in the wild": services for families with children at-risk”, Learning, Culture and Social Interaction, Vol. 13, pp. 23-37.

Ivaldi, S. and Scaratti, G. (2016), "The formation of germ cell for organizational learning”, Journal of Workplace Learning, Vol. 28 No. 4, pp. 224-244.

Ivaldi, S. and Scaratti, G. (2020), "Narrative and conversational manifestation of contradictions: Social production of knowledge for expansive learning", Learning, Culture and Social Interaction, Vol. 25, pp. 1-13. 
Juutilainen, M., Metsäpelto, R.-L. and Poikkeus, A.-M. (2018), "Becoming agentic teachers: Experiences of the home group approach as a resource for supporting teacher students' agency", Teaching and Teacher Education, Vol. 76, pp. 116-125.

Kumpulainen, K., Kajamaa, A. and Rajala, A. (2018), "Understanding educational change: Agencystructure dynamics in a novel design and making environment", Digital Education Review, No. 33, pp. 26-38.

Lipponen, L. and Kumpulainen, K. (2011), “Acting as accountable authors: Creating interactional spaces for agency work in teacher education", Teaching and Teacher Education, Vol. 27 No. 5, pp. 812-819.

Morselli, D. (2019), The Change Laboratory for Teacher Training in Entrepreneurship Education: A New Skills Agenda for Europe, Springer Nature, Cham.

Morselli, D. and Sannino, A. (2021), "Testing the model of double stimulation in a Change Laboratory", Teaching and Teacher Education, Vol. 97, pp. 1-8.

Nuttall, J., Thomas, L. and Henderson, L. (2018), "Formative interventions in leadership development in early childhood education: the potential of double stimulation", Journal of Early Childhood Research, Vol. 16 No. 1, pp. 80-91.

OECD (2018), "The future of education and skills. Education 2030", available at: www.oecd.org/ education/2030/E2030\%20Position \%20Paper\%20(05.04.2018).pdf

Priestley, M., Biesta, G., and Robinson, S. (2015), “Teacher agency: what is it and why does it matter?", in Kneyber, R. and Evers, J. (Eds), Flip the System. Changing Education from the Bottom up, Routledge, London, pp. 134-148.

Sannino, A. (2008), "From talk to action: Experiencing interlocution in developmental interventions", Mind, Culture, and Activity, Vol. 15 No. 3, pp. 234-257.

Sannino, A. (2011), "Activity theory as an activist and interventionist theory", Theory and Psychology, Vol. 21 No. 5, pp. 571-597.

Sannino, A. (2015), "The principle of double stimulation: a path to volitional action", Learning, Culture and Social Interaction, Vol. 6, pp. 1-15.

Sannino, A. (2016), "Double stimulation in the waiting experiment with collectives: Testing a Vygotskian model of the emergence of volitional action", Integrative Psychological and Behavioral Science, Vol. 50 No. 1, pp. 142-173.

Sannino, A. and Sutter, B. (2011), "Cultural-historical activity theory and interventionist methodology: classical legacy and contemporary developments", Theory and Psychology, Vol. 21 No. 5, pp. 557-570.

Sannino, A. and Laitinen, A. (2015), "Double stimulation in the waiting experiment: Testing a Vygotskian model of the emergence of volitional action", Learning, Culture and Social Interaction, Vol. 4, pp. 4-18.

Sannino, A., Engeström, Y. and Lahikainen, J. (2016), "The dialectics of authoring expansive learning: tracing the long tail of a change laboratory", Journal of Workplace Learning, Vol. 28 No. 4, pp. 245-262.

Sannino, A., Engeström, Y. and Lemos, M. (2016), "Formative interventions for expansive learning and transformative agency", Journal of the Learning Sciences, Vol. 25 No. 4, pp. 599-633.

Sannino, A. and Engeström, Y. (2017), "Co-generation of societally impactful knowledge in change laboratories", Management Learning, Vol. 48 No. 1, pp. 80-96.

Tao, J. and Gao, X. (2017), "Teacher agency and identity commitment in curricular reform", Teaching and Teacher Education, Vol. 63, pp. 346-355.

van der Veer, R. and Valsiner, J. (1991), Understanding Vygotsky: A Quest for Synthesis, Blackwell.

Virkkunen, J. (2006), "Dilemmas in building shared transformative agency", Activités, Vol. 3, pp. 44-66.

Virkkunen, J. and Newnham, D.S. (2013), The Change Laboratory. A Tool for Collaborative Development of Work and Education, Sense, Rotterdam. 
JWL 33,7

Vygotsky, L.S. (1978), Mind in Society: The Development of Higher Psychological Processes, Harvard University, Cambridge.

Vygotsky, L.S. (1997), "The historical meaning of the crisis in psychology. A methodological investigation", The Collected Works of LS Vygotsky: Problems of the Theory and History of Psychology, Plenum, New York, NY, Vol. 3.

Wallen, M. and Tormey, R. (2019), "Developing teacher agency through dialogue", Teaching and Teacher Education, Vol. 82, pp. 129-139.

\section{Corresponding author}

Daniele Morselli can be contacted at: daniele.morselli@unibz.it

For instructions on how to order reprints of this article, please visit our website: www.emeraldgrouppublishing.com/licensing/reprints.htm

Or contact us for further details: permissions@emeraldinsight.com 